\title{
Depression and Suicide
}

National Cancer Institute

\section{Source}

National Cancer Institute. Depression and Suicide. NCI Thesaurus. Code C6768.

Studies which look at the causal relationship between depression and suicide. 